\title{
A DEMOCRATIZAÇÃO DA EDUCAÇÃO E SEU VÍNCULO À CONSOLIDAÇÃO DO IDEARIO LIBERAL NO PAÍS: ALGUNS APONTAMENTOS
}

\author{
Celso Hotz ${ }^{1}$ \\ Isaura Monica Souza Zanardini ${ }^{2}$
}

\section{RESUMO}

Neste artigo apresentamos reflexões sobre o processo de democratização da educação no Brasil, analisando seus vínculos para a consolidação do ideário liberal no país. Não obstante a reivindicação da educação por parte de setores progressistas da sociedade brasileira, via de regra a educação tem sido indicada (ou sua falta), como responsável pelas disfunções inerentes ao modo capitalista de produção da existência. Desta forma, a democratização da educação tem se constituído como estratégia ideológica requerida pelos liberais, para o atendimento de seus interesses de classe, na justificativa do acesso ao emprego pela competência e meritocracia, na defesa de um ensino dual e no controle da mão-de-obra, todos, como reforçadores da proposição societária capitalista e de sua concretização no Brasil.

Palavras-chaves: Democratização da Educação; liberalismo; ascensão social pela escolarização.

\section{THE DEMOCRATIZATION OF THE EDUCATION AND HIS BOND TO THE LIBERAL INTERESTS: SOME NOTES}

\begin{abstract}
In this article we present reflections on the process of democratization of the education in Brazil, analysing its bonds for the consolidation of the liberal ideas in the country. Despite the claim of education by progressive sectors of Brazilian society, in general education has been indicated, (or it lack), like responsible for the dysfunctions inherent in the capitalist way of production of the existence. In this way, the democratization of the education has been constituted like ideological strategy applied by the liberals, for the service of theirinterests of class, in the justification of the access to the job for the competence and meritocracy, in the defense of a dual teaching and in the control of the labor, all, like reforcers of the societarian capitalist proposition and of its realization in Brazil.

Keywords: Democratization of the Education; liberalism; social ascension for the schooling.
\end{abstract}

\section{Introdução}

Nosso objetivo, neste artigo, é apresentar algumas reflexões sobre o processo de realização da democratização da educação ${ }^{3}$ no Brasil, procurando apreender sua contribuição à consolidação do ideário liberal, compreendendo esta consolidação no âmbito da luta de classes historicamente constituída no país.

A ideologia liberal tem estado presente nas discussões acerca da educação há longa data no Brasil, sobretudo, a partir da década de 1920, quando questões como laicidade, universalidade, gratuidade e democratização de acesso à educação têm sido discutidos no contexto do que se conhece como otimismo pedagógico e entusiasmo pela educação ${ }^{4}$. 
Apesar do presente artigo não ter a pretensão de focalizar no profícuo debate ocorrido entre o grupo dos liberais e o grupo dos católicos, nos primórdios das primeiras políticas educacionais implementadas no Brasil, entende-se que tal debate aprofundou a questão da democratização do ensino no país, e dentre os pensadores que compunham o grupo de educadores liberais, pode-se citar Anísio Teixeira, Fernando de Azevedo e Lourenço Filho, e do grupo de defensores católicos pode-se citar como o principal expoente, Alceu Amoroso Lima.

A educação, como uma das políticas sociais implementadas pelo Estado brasileiro desde a década de 1920, e como produto dos embates e conflitos entre as classes sociais, vai sendo reivindicada pela classe proletária paulatinamente concentrada nas cidades, devido à crescente industrialização e as decorrentes necessidades de urbanização inerentes às novas forças produtivas no Brasil naquele período.

Em seus aspectos contraditórios de atendimento às reivindicações sociais $\mathrm{e}$ reprodução da exploração do capital, as políticas sociais se constituem em "[...] respostas do Estado burguês do período do capitalismo monopolista a demandas postas no movimento social por classes (ou estratos de classes) vulnerabilizados pela 'questão social"” (NETTO, 2003, p.15).

A legitimação de um ideário liberal tem contado, pois, com a contribuição das políticas educacionais desde o processo de industrialização brasileira, intensificando-se através da proposição desenvolvimentista, engendrada na década de 1930, coforme aponta Fiori (2003). Neste contexto desenvolvimentista, a educação formal tem sido enfatizada como uma das estratégias do Estado para o desenvolvimento econômico nacional ${ }^{5}$.

$\mathrm{Na}$ medida em que, de certo modo, atende a uma demanda social, a democratização da educação também vai se incorporando como instrumento de ajuste da oferta de mão-deobra disponível para o mercado de trabalho, e esta incorporação é apropriada pela classe dominante para a construção de uma pedagogia da hegemonia ${ }^{6}$, sobretudo, através do poder estatal.

Um dos argumentos ideológicos do liberalismo aponta a educação, seja pela sua ausência ou por sua falta de qualidade, como justificativa das disfunções inerentes ao modo capitalista de produção da existência, como, por exemplo, a exclusão social e a falta de acesso aos bens materiais necessários à sobrevivência.

Uma interessante conceituação do movimento liberal pode ser apanhada das discussões que embalaram a implementação da Lei 4.024/61:

O liberalismo também teve sua vez. Só que se tratou quase sempre de um liberalismo ambíguo. Contestava o predomínio das estruturas arcaicas do campo sobre as aspirações modernizantes das cidades. Ou advogava a necessidade de eleições limpas, de instituições como o habeas corpus ou o mandado de segurança. Enaltecia as virtudes da livre competição, seja ela econômica ou política. No entanto menos cultivava a liberdade do que era produto dela. Ou seja: produto de certas situações favoráveis, elas próprias ligadas às extremas desigualdades da sociedade brasileira. Situações essas que franqueavam aos seus ocupantes, além de oportunidades especificas de lazer e de cultura, o exercício de uma crítica - na imprensa, nas assembleias legislativas, nos tribunais - ao mesmo tempo impiedosa e inócua em relação à estrutura de autoridade vigente na sociedade brasileira. Mesmo porque a existência dos próprios liberais e, portanto, a condição de possibilidade da sua crítica assentava nessa estrutura (DEBRUN apud SAVIANI, 2006, p. 47). 
Por outro lado, a partir da contradição presente nas políticas sociais, pode-se apreender que a classe trabalhadora tem feito uso da escola como forma de ampliação de seus direitos sociais, e que o Estado burguês coloca-se, pois, num importante papel quanto à instituição das condições que possibilitem o avanço e consolidação do capitalismo e do ideário liberal no Brasil, inclusive por meio das políticas educacionais.

\section{A democratização da educação e seu vínculo aos interesses liberais}

A categoria democracia é, pode-se assim dizer, pertinente e recorrente a um modo de produção, que se realiza a partir da naturalização da exploração de uma classe sobre a outra, sendo de um lado demanda das classes em luta, e de outro, estratégia de sobrevivência das frações que constituem as classes, com predomínio de interesses da burguesia.

Tal predomínio de uma classe sobre as demais é naturalizado pelos liberais, inclusive no argumento de que um "bem-estar comum” não seja socialmente viável:

Não é difícil perceber o que acontece quando a democracia dá início a uma linha de planejamento cuja execução exige um consenso muito maior do que na realidade existe. É possível que o povo tenha concordado com a adoção de um sistema de economia planificada por ter-se deixado persuadir de que tal sistema contribuirá para criar uma grande prosperidade. Nos debates que conduziram à decisão, o objetivo do planejamento foi talvez designado por algum termo como "bem-estar comum", termo que apenas oculta a ausência de um verdadeiro acordo sobre tal objetivo (HAYEK, 1990, p. 77).

O tema "democratização", embora sempre presente, esteve em discussão na sociedade brasileira desde a década de 1920, sendo resgatada em grandes discussões na sociedade em vários períodos históricos, como por exemplo, na transição de governos militares a governos republicanos, como nos pós 1945 e 1985.

Há diferentes análises sobre a democracia e o que a caracteriza. Cunha (1991), por exemplo, que analisa a democracia ou mesmo a sua falta a partir do direito ao voto, classifica em cinco períodos a organização político-social no Brasil, como segue: eleitores;

a) $1^{\circ}$ período: Imperial, baseado na escravidão e, deste modo, na restrição de

b) $2^{\circ}$ período (1880-1930): Primeira República, marcado também pela restrição de eleitores, pois as mulheres e analfabetos eram excluídos das eleições;

c) $3^{\circ}$ período: Ditatorial (1930 a 1945), centralizador que descaracteriza a participação popular;

d) $4^{\circ}$ período: segundo Cunha, "nossa primeira experiência democrática" (1946 a 1964), onde movimentos sociais influenciam a condução do Estado;

e) $5^{\circ}$ período: marcado pelo golpe de março de 1964 (1964 a 1982): restrições à liberdade política.

Entretanto, se partirmos do entendimento de que o Estado brasileiro desde sua constituição é ocupado por frações ${ }^{7}$ de poder, as quais representam, via de regra, interesses do bloco dominante (internos ou externos ao país), a democratização, em grande parte, esteve naqueles momentos históricos atrelada à rearticulação das forças hegemônicas em disputa pelo poder estatal, pois 
[...] às frações burguesas não-hegemônicas se abrem duas alternativas de luta: a) eleição do golpe militar como via de acesso à hegemonia política (alternativa que tende a ser escolhida quando tal luta se desenvolve num quadro marcado pela gestação/crescimento de um movimento revolucionário de massa; b) escolha, como via de acesso à hegemonia política, do terreno eleitoral, o que implica uma posição de defesa das instituições políticas democráticas (ali onde elas existem), e de luta pela sua ampliação (ali onde são restritas) ou criação (ali onde elas inexistem) (SAES, 1994, p. 176).

Na lógica desse autor, a utilização da democracia pela burguesia para atingir o poder estatal pela via eleitoral, pode "[...] tanto servir como instrumento de reforço da dominação ideológica burguesa, como levar ao desenvolvimento da consciência revolucionária do proletariado" (SAES, 1994, p. 172).

Sob essa perspectiva, o caráter de classe do Estado burguês brasileiro, que o coloca como grande responsável pela reprodução e ampliação do acúmulo de capital, evidencia o limite da democracia na sociedade capitalista.

Nos valemos aqui de Saes (2001), para indicar que, embora seja necessária à classe proletária $^{8}$, a democracia é utilizada pela burguesia, neste contexto, como indispensável para a manutenção e consolidação de seu poder político-econômico.

$\mathrm{Na}$ busca pela igualdade material na sociedade, a classe proletária historicamente tem ampliado sua luta contra a burguesia, a qual faz uso da igualdade política formal, garantida pelos direitos jurídico-políticos através do Estado de classes, para legitimar sua dominação na sociedade capitalista. Nesta luta histórica,

A contradição, própria às democracias burguesas, entre a igualdade política formal e a desigualdade econômico-material é insuficiente para revelar ao proletariado a existência de um processo (capitalista) de exploração do trabalho. Ela pode, entretanto, fornecer àquela parcela do proletariado, já conhecedora (de modo mais ou menos instintivo, mais ou menos elaborado) de sua situação de classe explorada, a chave do enigma do Estado: o seu caráter de classe (SAES, 1994, p.171-172).

É a partir destes pressupostos que o discurso da democratização da educação no Brasil tem se constituído em grande medida numa estratégia de concretização das intenções de dominação burguesa, via políticas educacionais advindas de embates de classes, e implementadas pelo Estado burguês aqui consolidado, e ocupado por frações de poder burguesas nos diferentes momentos históricos do país.

De outro lado, a luta pela democratização da educação e o desvelamento da impossibilidade de sua realização plena numa sociedade capitalista, pode constituir-se em instrumento na luta pelo rompimento das relações sociais vigentes, sobretudo, para a classe proletária.

Com a proposição econômica desenvolvimentista, vivenciada no Brasil a partir de $1930^{9}$, o país aprofundou seu alinhamento aos "padrões" de desenvolvimento dos países centrais do capitalismo, o que já vinha sendo posto em prática através dos vários governos alinhados, sobretudo, aos ideais liberais que se seguiram, a partir da constituição do Estado burguês.

Tendo em vista que em meio à divisão internacional do trabalho e as relações postas entre os países centrais e periféricos, o Brasil tem desempenhado papel de dependência em relação aos países centrais, e a estratégia desenvolvimentista reforçou esta condição, na medida em que tinha como principal meta, a viabilização das condições 
materiais necessárias ao pleno desenvolvimento do capitalismo aqui existente, afim de "impulsionar" o país ao patamar das nações desenvolvidas.

É na busca constante pelo desenvolvimento endógeno do capitalismo, que a dependência aos países do núcleo capitalista foi se expandindo, por um lado pela entrada cada vez mais crescente de produtos do primeiro setor da produção industrial que contou com a instalação de empresas multinacionais, e por outro, pela entrada maciça de capitais externos na forma de financiamento, que sob a tutela dos países centrais têm promovido as condições financeiras e ideológicas necessárias aos países periféricos para a consolidação do projeto societário capitalista.

A lógica liberal fundamenta este projeto societário, centralizando as decisões financeiras e ideológicas a serviço do capital:

A democracia exige que as possibilidades de controle consciente se restrinjam aos campos em que existe verdadeiro acordo, e que, em certos campos, se confie no acaso: este é o seu preço. Mas numa sociedade cujo funcionamento está subordinado ao planejamento central não se pode fazer com que esse controle dependa da possibilidade de um acordo de maioria; muitas vezes será necessário impor ao povo a vontade de uma pequena minoria, porque esta constitui o grupo mais numeroso capaz de chegar a um acordo sobre a questão em debate. O governo democrático funcionou de modo satisfatório nos casos em que, por força de uma convicção amplamente difundida, as funções governamentais se restringiam aos campos em que se podia alcançar um acordo de maioria pelo livre debate - e só funcionou enquanto isso foi possível. O grande mérito da doutrina liberal é ter reduzido a gama de questões que dependem de consenso a proporções adequadas a uma sociedade de homens livres. Muitos dizem, no atual momento, que a democracia não tolerará o "capitalismo". Se na acepção dessas pessoas "capitalismo" significa um sistema de concorrência baseado no direito de dispor livremente da propriedade privada, é muito mais importante compreender que só no âmbito de tal sistema a democracia se torna possível. No momento em que for dominada por uma doutrina coletivista, a democracia destruirá a si mesma, inevitavelmente (HAYEK, 1990, p. 82).

$\mathrm{Na}$ esteira do desenvolvimento econômico acelerado, proposto sob a égide da ideologia desenvolvimentista, a democratização da educação é utilizada, também no campo ideológico, como "possibilidade" de acesso da maioria da população aos "benefícios" do capital, principalmente através da ascensão social via escola (o que não passa também de uma estratégia ideológica), e de formação de consumidores.

A partir deste contexto, a ênfase dada na democratização da educação pela burguesia nacional e internacional, enquanto ampliação da possibilidade de acesso, sobretudo nos níveis iniciais de ensino, busca justificar a exclusão "natural" do sistema capitalista por meio da meritocracia e competência individuais, ambos tomados como legitimadores do acesso ao trabalho e aos bens de consumo.

Cabe destacar que neste contexto, também estavam colocadas as demandas de ampliação educacional da nascente classe média que também acenavam como garantias de maior participação econômica e política.

No âmbito da estratégia desenvolvimentista, e numa possível análise da função da educação neste processo, 
É interessante verificar que, ao contrário do que com frequiência se supõe, o discurso desenvolvimentista não concebia ou apresentava a educação como condição para o desenvolvimento. O país não podia esperar as reformas educacionais; estas é que deveriam acompanhar o processo de crescimento econômico para atender às suas exigências, conforme elas fossem emergindo (XAVIER, 2007, p. 18).

Assim, a defesa pelos liberais da democratização do acesso à educação no Brasil, articula-se aos requisitos necessários para a criação de um consenso em torno dos benefícios do desenvolvimento econômico do país, de modo que nos planos de desenvolvimento governamentais, difunde-se a

[...] idéia universalista de que a educação escolar poderia assegurar, para todos os que passassem pela escola, o direito a ascender socialmente de sua condição de trabalhador à de detentor dos meios de produção, isto é, realizar, já na terra, a abundância material, cultural e espiritual que concretiza o ápice da felicidade humana de todos (NOGUEIRA, 2007, p. $65)$.

Como resultado da concentração processual da população nos grandes centros industriais, a industrialização incipiente veio acompanhada da necessidade de políticas sociais, dentre elas as políticas educacionais, até mesmo pela capacidade de reivindicação gerada a partir da concentração populacional nas grandes cidades, que demandava uma determinada modernização ligada ao processo de urbanização próprio das sociedades industriais.

E no âmbito educacional,

Esse crescimento industrial, tão lento e incipiente que não acarretava por si mesmo a exigência de qualificação para o trabalho, mas que representava um salto qualitativo no avanço das relações de produção no país, acabou por fortalecer a difusão da ilusão liberal de ascensão social pela escolarização, que a própria aceleração do progresso imigratório estimulava (XAVIER, 1990, p. 62).

Ainda aliado ao ideário liberal, e em consolidação nas políticas públicas para a educação, explicitava-se, desde o período de 1920-30 no Brasil, "[...] a crença na possibilidade de reformar a sociedade pela reforma do homem" (NAGLE, 2001, p. 134). A esta crença somaram-se ainda os chamados entusiasmo pela escolarização e otimismo pedagógico, nos debates que culminaram, em 1932, no Manifesto dos Pioneiros da Educação Nova.

O combate ao analfabetismo da população nacional e, deste modo, a luta pela ampliação do acesso à escola, estava articulado, sobretudo, pelo discurso liberal que apontava a inserção do país no patamar "civilizatório" a partir da escola, sob a luz das grandes potências mundiais, ao mesmo tempo em que se ligava a fins eleitorais, à preparação de mão-de-obra e de consumidores em potencial.

Como resultado desse discurso, e mais do que isso, das relações sociais que o produziam, a realidade explicitava um ensino dualista, pois de um lado oferecia às elites burguesas brasileiras a preparação para conduzir os rumos do país e, de outro, oferecia ao trabalhador a preparação para o mercado de trabalho. $O$ ponto alto desta distinção caracterizou-se na "[...] preocupação constante com a implantação do regime universitário no país, o único capaz de preparar eficazmente as 'verdadeiras elites dirigentes' para 
realizar as novas tarefas impostas pelas exigências do mundo contemporâneo" (NAGLE, 2001, p. 161).

O ideário liberal aqui constituído reforçou a função equalizadora assumida pela educação, na medida em que "[...] expandir as oportunidades educacionais ou reformar as instituições escolares representava um custo menor que alterar a distribuição de renda e as relações de poder" (XAVIER, 1990, p. 63).

As reformas governamentais para o ensino público que se seguiram nas décadas de 1930-40, sobretudo as reformas Francisco Campos (1931) e Capanema (1942), legitimaram a

[...] oficialização do dualismo educacional brasileiro que reproduzia, na estrutura do sistema educacional, a discriminação e os privilégios da estrutura econômico-social, mantidos e garantidos tanto no regime político 'democrático' como no 'autoritário', sob o respaldo ideológico de 'conservadores' e 'liberais'. A política educacional nacional definiase, cada vez mais nitidamente, como instrumento de cimentação da ordem econômico-social vigente (XAVIER, 1990, p. 119).

O que podemos perceber, analisando este período histórico, é que "Se a educação era concebida como panacéia para todos os males nacionais, o era na medida em que forjava elites cultas e esclarecidas para a condução dos destinos da nação" (XAVIER, 1990, p. 139), ao mesmo tempo em que formava os quadros necessários às exigências produtivas.

Desta forma, a democratização da educação imbricava-se à função ideológica por ela ocupada, na busca pelo desenvolvimento das forças produtivas e capitalistas no país.

Dado o caráter classista que a política educacional vem assumindo historicamente no Brasil, articulando um ensino dual através de formações específicas e distintas para o trabalhador e para a elite nacional, sua função não poderia ser diferente da reprodução da sociedade que se alicerça no acúmulo do capital e na divisão de classes, consolidando-se como estratégia ideológica requerida constantemente pelos liberais ocupantes ou não do poder estatal. Como já nos ensinara Tragtenberg, "[...] a escola não cria a divisão em classes, mas contribui para esta divisão e reprodução ampliada" (2002, p. 22).

A defesa da educação como solução aos problemas sociais característicos da proposição capitalista, oculta, entretanto, o fato de que

O processo brasileiro de industrialização não resultou de um avanço técnico propiciado pelo desenvolvimento científico e tecnológico do país. O processo de produção e transmissão do saber não constituiu, no Brasil, uma base ou um elemento propulsor da mudança nas relações de produção. Essa é uma das facetas típicas do capitalismo que no processo da reprodução do capital em escala mundial se instala e avança em formações sociais 'atrasadas' nas quais nem todas as condições internas necessárias a esse avanço estão presentes. As novas formas de produção foram aqui absorvidas como parte do movimento de expansão da moderna civilização ocidental, que consolidou o avanço das relações capitalistas em nível internacional (XAVIER, 1990, p.57).

Deste modo, a falta da educação da população tem servido ideologicamente como justificativa à miséria social e aos "atrasos" do país, tanto nos aspectos econômico como social; fato este que tem levado os governos brasileiros, movimentos sociais, investidores 
externos e uma parcela significativa de educadores, a defender a bandeira da democratização da educação, principalmente das séries iniciais de ensino.

A convergência de interesses distintos para a defesa da democratização da educação esteve diretamente vinculada aos benefícios econômico-sociais que a educação eventualmente poderia trazer, sobretudo aos países periféricos. Esta idéia desconsidera, entretanto, a contradição existente entre crescimento econômico e desenvolvimento social, pois a relação entre ambos não é proporcional, já que altos índices de crescimento econômico nem sempre propiciam o desenvolvimento social de um país.

No que diz respeito aos anos de 1960, a incorporação da educação como imprescindível ao desenvolvimento econômico do país, evidenciou-se, também, nos planos de desenvolvimento elaborados a partir da ditadura militar (1964), os quais, em linhas gerais, tiveram o combate ao analfabetismo e a proposição do ensino técnico como traduções da democratização da educação, e como principais metas dos governos que se seguiram no período de 1964 a 1985, para a área educacional.

A função terminal do ensino técnico propugnado na política educacional dos governos militares no Brasil, a fim de conter o acesso ao nível superior de ensino, destinado somente às elites, não se efetivou por vários fatores, dentre os quais: a falta de recursos para implantação dos cursos profissionalizantes; a não contenção da demanda pelo ensino superior; a falta de profissionais preparados para ministrar aulas; a evasão escolar, e ainda, devido ao ingresso antecipado no mercado de trabalho formal ou informal (CUNHA, 1978).

Como indica Cunha, a racionalização levada a cabo pela reforma universitária de 1968 corroborou com esse processo, pois

A partir de 1964 intensificou-se o processo econômico de concentração de propriedade, capital, renda e mercado, devido à política econômica, adotada a partir daí. Houve, então, grande quantidade de falências de pequenas empresas durante a recessão a partir do primeiro semestre desse ano. Com isso, ficavam mais dificultadas as possibilidades de ascensão da classe média via poupança, investimento e reprodução do capital, através da instalação de pequenas empresas, artesanatos e de exercícios de profissão liberal. Em consequência, a demanda do ensino superior aumentou de modo que o crescimento das matrículas resultou insuficiente diante de uma procura cada vez maior. No período 1964-1968 o número de candidatos às escolas superiores cresceu de $120 \%$, taxa superior à elevação do número de vagas que foi de $56 \%$ no mesmo período (CUNHA, 1978, p.238-239).

A alfabetização, funcionando como medida de liberação ao ensino inicial foi desenvolvida no período ditatorial através da educação formal e não formal, sendo esta última compreendida pelo Movimento Brasileiro de Alfabetização (MOBRAL) ${ }^{10}$, pelo projeto Minerva (educação via rádio) e também via TV, no atendimento massivo de adolescentes, pré-adolescentes e adultos (CUNHA, 1978, p. 286). Movimento esse que foi concretizado como contraponto aos movimentos de cultura popular ${ }^{11}$, férteis no período pré-golpe militar dos anos 1960.

As funções das políticas educacionais de liberação, e, portanto, de democratização, articulavam-se, sobretudo, à ampliação do mercado de mão-de-obra de reserva e do mercado de consumo; ao controle social através das mensagens implícitas legitimadoras da ordem social capitalista, uma vez que funcionavam equalizando o acesso aos níveis educacionais de acordo com a demanda econômica e também política. (CUNHA, 1978). 
Neste aspecto, tanto as políticas de liberação das séries iniciais quanto das de contenção ao nível superior de ensino nos governos militares, apontavam para "[...] o alcance de uma mesma e única meta: a reprodução das classes sociais e das relações de dominação que as definem, sustentam e dão vida" (CUNHA, 1978, p. 288).

A partir dos anos 1980, a democratização do acesso à escola é recomendada pelo conjunto de reformas educacionais sustentadas por organismos internacionais, como requisito primordial da promessa de desenvolvimento econômico e social. Coloca-se a partir deste contexto, a ênfase na universalização do ensino fundamental e na erradicação do analfabetismo, recuperando o princípio liberal da igualdade de oportunidades.

Essa perspectiva de democratização do acesso aos anos iniciais da educação básica é acompanhada pelo princípio constitucional da gestão democrática, o qual promoveria o envolvimento da comunidade no que diz respeito à proposta pedagógica da escola, e desse modo, a responsabilização pelos resultados alcançados, o que na lógica do pensamento liberal levaria à superação de uma suposta crise de eficiência da escola e de sua democratização.

Apesar de um determinado incentivo de acesso ao ensino superior, observa-se que o princípio da contenção também está presente nos anos 1990 por meio das políticas de educação profissional, as quais atendem à classe trabalhadora que, tendo concluído o ensino fundamental, vê nesta modalidade de ensino a possibilidade de certificação necessária ao ingresso no mercado de trabalho.

\section{Algumas Considerações}

As análises feitas neste trabalho, a partir dos autores que tratam sobre a democratização, indicam, de certa forma, a sua "captura" pelos setores hegemônicos, que a tem utilizado para efetivar seus interesses de classe, inclusive incorporando-a na defesa pelo acesso à escolarização.

Esta "captura" da democratização da educação, dá sustentação à ideologia que coloca os fracassos do capitalismo como inerentes à falta de escolarização da população, ao mesmo tempo em que funciona como mecanismo de controle de mão-de-obra disponível no mercado, ao conter o acesso aos níveis de ensino superior e "liberar" o acesso aos níveis iniciais de escolarização.

De outro lado, a expansão da democratização da educação atende, em relativa medida, aos anseios tanto dos extratos médios como de uma parcela significativa dos trabalhadores.

A estratégia da utilização da democratização da educação pelos liberais, remonta às primeiras políticas educacionais implementadas pelo Estado brasileiro, e vem se acirrando através dos mecanismos de difusão da ideologia liberal, principalmente por meio das políticas públicas de ensino, colocadas em prática pelo Estado de classes.

Dentro da proposição desenvolvimentista brasileira, o ideário liberal, que colocava o mito da ascensão social pela educação, pôde encontrar maiores oportunidades de disseminação.

Nos limites da análise ora realizada, é possível afirmar que os objetivos da defesa da democratização da educação pelos liberais, historicamente está ligada à sua utilidade para a legitimação de seus interesses de classe, que são concretizados, por exemplo: pelo uso da educação no controle do trabalho excedente, justificando o acesso ao emprego pela competência e meritocracia, que a ideologia liberal diz ser adquirida pelos "longos" anos de escolarização; pelo uso da educação na justificativa das mazelas do capitalismo, pois a miséria social é resultado (no discurso liberal) do subdesenvolvimento do país, o qual, por consequiência, se dá pela falta de escolarização da população; pelo uso da educação na 
difusão dos preceitos liberais de que todos são iguais perante a lei, e assim são tratados "igualmente" na sociedade capitalista.

Como apresenta vastos limites para uma mudança significativa na ordem da sociedade de classes, a democratização da educação vem se constituindo no reforço desta sociedade, através da dualidade do ensino (para os trabalhadores um ensino que direcione e prepare para o trabalho; para a classe dominante um ensino que direcione a cargos altamente remunerados), e que permita sua manutenção no controle político por meio da elitização do ensino, com o acesso aos níveis superiores de ensino somente a uma minoria.

Assim, sob a tutela do capitalismo defendida pelos preceitos liberais, a democratização da educação no Brasil tem sido acompanhada pela perda de qualidade, e deste modo, caracterizada por altos índices de abandono, de retirada processual das responsabilidades do Estado, da falta de acesso aos níveis superiores de ensino à maioria da população, e, enfim, por condições que contribuem para a reprodução do modo capitalista de produção da existência.

Este tem se constituído no projeto de democratização da burguesia nacional e internacional, e que tem encontrado respaldo nas políticas sociais implementadas pelo Estado burguês brasileiro, dentre elas, a política educacional.

\section{Referências}

CUNHA, Luis Antonio. Educação e desenvolvimento no Brasil. Rio de Janeiro: Francisco Alves, 1978.

- Educação, Estado e democracia no Brasil. São Paulo: Cortez; Niterói, RJ: FLACSO do Brasil, 1991.

CUNHA, Luiz Antônio e GOÉS, Moacyr de. O golpe na educação. 7. ed. Rio de Janeiro: J.Z.E., 1991.

FIGUEIREDO, Ireni Marilene Zago. A construção da "centralidade da educação básica" e a política educacional paranaense. Cascavel: Edunioeste, 2005.

FIORI, José Luís. $O$ vôo da coruja. Para reler o desenvolvimentismo brasileiro. Rio de Janeiro: Record, 2003.

GADOTTI, Moacir. História das Ideias Pedagógicas - Série Educação , Ed. 8, Editora: Ática, 2003.

HAYEK, Friedrich August von. O caminho da servidão . Tradução e revisão Anna Maria Capovilla, José Ítalo Stelle e Liane de Morais Ribeiro. 5. ed. Rio de Janeiro: Instituto Liberal, 1990. Disponível em http://ordemlivre.org/posts/o-caminho-da-servidao-f-ahayek--14> Acesso em 17 dez 2014.

LENIN, Vladimir. O Estado e a Revolução In: Obras Escolhidas. Vol. 2. São Paulo: AlfaOmega, 1980.

NAGLE, J. Educação e sociedade na primeira república. 2. ed. Rio de Janeiro: DP\&A, 2001. 
NETTO, José Paulo. Capitalismo monopolista e serviço social. 2. ed. São Paulo: Cortez, 1996.

O materialismo histórico como instrumento de análise das políticas sociais. In: NOGUEIRA, F.M.G; RIZZOTTO, M.L.F.(Orgs.). Estado e políticas sociais: Brasil Paraná. Cascavel: Edunioeste, 2003.

NEVES, L. M. W. A sociedade civil como espaço estratégico de difusão da nova pedagogia da hegemonia. In: NEVES, L. M. W (org.). A nova pedagogia da hegemonia: estratégias do capital para educar o consenso. São Paulo: Xamã, 2005.

NOGUEIRA, Francis Mary Guimarães. As proposições para a educação escolar expressas nos planos de desenvolvimento do regime militar in: NOGUEIRA, F.M.G; RIZZOTTO, M.L.F.(Orgs.) Políticas sociais e desenvolvimento: América Latina e Brasil. São Paulo: Xamã, 2007.

SAES, Décio. Estado e democracia: ensaios teóricos. 2. ed. Campinas: Unicamp, Instituto de Filosofia e Ciências Humanas, 1994 (coleção Trajetória, 1).

SAES, Décio. A evolução do Estado no Brasil (uma interpretação marxista) In: SAES, D. República do capital: capitalismo e processo político no Brasil. São Paulo: Boitempo Editorial, 2001.

SAVIANI, Dermeval. História das Ideias Pedagógicas no Brasil. 2008. Campinas, SP: Autores Associados.

Política e educação no Brasil: o papel do Congresso Nacional na legislação do ensino. Campinas, SP: Autores Associados, 2006.

TAVARES, Maria da Conceição; FIORI, José Luís. (Des)Ajuste global e modernização conservadora. Rio de Janeiro: Paz e Terra, 1993.

TRAGTENBERG, Mauricio. A escola como organização complexa. In: Revista Espaço Acadêmico. Ano II, volume 12, maio de 2002. Maringá, PR.

XAVIER, Maria Elizabete Sampaio Prado. Educação e desenvolvimento: uma retrospectiva histórica da construção da crença no poder da educação na sociedade brasileira in: NOGUEIRA, F.M.G; RIZZOTTO, M.L.F.(Orgs.) Políticas sociais $e$ desenvolvimento: América Latina e Brasil. São Paulo: Xamã, 2007.

Capitalismo e escola no Brasil: a constituição do liberalismo em ideologia educacional e as reformas do ensino (1931 - 1961). Campinas/SP: Papirus, 1990.

\footnotetext{
${ }^{1}$ Mestre em Educação pela UNIOESTE. Docente da Universidade Tecnológica Federal do Paraná Campus de Francisco Beltrão, atuando no curso de Licenciatura em Informática. Pesquisador do Observatório Paranaense de Tecnologias de Informação e Comunicação e Sociedade (OPTICS). E-mail: chotz@bol.com.br

${ }^{2}$ Doutora em Educação pela UNICAMP. Docente Associada da Universidade Estadual do Oeste do Paraná Campus de Cascavel, atuando nos cursos de graduação em pedagogia e mestrado em Educação. Pesquisadora
} 
do Grupo de Estudos e Pesquisas em Política Educacional e Social (GEPPES). E-mail: monicazan@uol.com.br

${ }^{3}$ Entendemos a democratização da educação como o acesso à escolarização pela maioria da população aos diversos níveis de ensino. Porém, historicamente, se verifica nas políticas educacionais a preocupação do combate ao analfabetismo, o que pressupõe a ênfase no acesso às séries iniciais do ensino fundamental. A esse respeito, ver, por exemplo, Figueiredo (2005).

4 Jorge Nagle (2001) é um dos principais pensadores que cunhou os termos otimismo pedagógico e entusiasmo pela educação. O Manifesto dos Pioneiros da Educação Nova (1932), sintetiza, de certa forma, as bandeiras defendidas pelo heterogêneo grupo de liberais que o assinaram. $\mathrm{O}$ entusiasmo pela escolarização caracterizou "[...] a crença de que, pela multiplicação das instituições escolares, da disseminação da educação escolar, será possível incorporar grandes camadas da população na senda do progresso nacional”; já o otimismo pedagógico explicitava "[...] a crença de que determinadas formulações doutrinárias sobre a escolarização indicam o caminho para a verdadeira formação do novo homem brasileiro (escolanovismo)" (NAGLE, 2001, p. 134).

5 Ao nos reportarmos a um período posterior onde ainda imperava a ideologia desenvolvimentista, a reconfiguração da "teoria do capital humano" de Theodore W.Schults durante as décadas de 1960 e 1970 no Brasil, reforçaram o papel de formação humana para o capital, prescrita pela escola oficial. Ver, dentre outros sobre o tecnicismo na educação brasileira: Cunha e Goés (1985) e Saviani (2008).

${ }^{6}$ Mesmo não dizendo respeito ao contexto histórico em questão, é relevante consultar a forma como Neves (2005) trabalha com o conceito de pedagogia da hegemonia no contexto do neoliberalismo, para a consolidação de um ideário consensual das reformas educacionais ocorridas a partir da década de 1990 no Brasil.

${ }^{7}$ De acordo com a análise de Saes "As diferentes classes e frações que exploram o trabalho de outrem exercem conjuntamente o poder político sobre as classes exploradas" (2001, p. 50), entretanto, “[...] detém a hegemonia no seio do bloco no poder a classe ou fração cujos interesses são prioritariamente contemplados pela política econômica e social do Estado" (Idem, p. 51).

${ }^{8}$ A respeito da relevância da democracia para a classe proletária, Lênin (1980, p. 289) afirma: "A democracia tem uma importância enorme na luta da classe operária contra os capitalistas pela sua libertação. Mas a democracia não é de modo nenhum um limite intransponível, mas apenas uma das etapas no caminho do feudalismo para o capitalismo e do capitalismo para o comunismo".

${ }^{9}$ Segundo Fiori, o modelo desenvolvimentista brasileiro foi posto em prática desde a década de 1930, e foi responsável, “[...] sobretudo depois de 1950, pela industrialização brasileira" (2003, p. 141), tendo sua fase terminal nos anos 1979-1982.

${ }^{10}$ O Movimento Brasileiro de Alfabetização (MOBRAL), criado em 1967, mas iniciado efetivamente a partir de 1970, foi um dos mais conhecidos programas educativos instituídos pelo Regime Militar, com objetivo prioritário de alfabetização da população urbana de 15 a 35 anos, sendo autorizado, a partir de 1974, a alfabetizar também a população de 9 a 14 anos de idade (CUNHA, 1978, p. 254).

${ }^{11}$ A esse respeito, sugerimos ver dentre outros: CUNHA e GOÉS (1991).

Recebido: fevereiro-14 Aprovado: dezembro-14 